\title{
Gedrag \& Organisatie door de jaren heen: een methodologische rondleiding
}

\author{
Toon Taris*, Jan de Jonge** \& Jan Fekke Ybema***
}

In deze studie wordt nagegaan in welke mate methodologische vernieuwingen in het arbeids- \& organisatie (A\&O-)psychologische instrumentarium van methoden en technieken doordringen in de praktijk van het A\&O-onderzoek. Eerst werd geïnventariseerd welke onderwerpen in de methodologische hoofdstukken van enkele A\&O-psychologische handboeken werden besproken. Op basis van een inhoudsanalyse van 67 in de perioden 1990/1991 en 2002/2003 in het tijdschrift Gedrag \& Organisatie verschenen empirische artikelen werd vervolgens bekeken welke van deze methoden daadwerkelijk door onderzoekers werden toegepast. Geconcludeerd wordt dat methodologische vernieuwingen wat betreft het instrumentarium en onderzoeksdesign grotendeels achterwege blijven, maar dat er wat betreft de analyse van gegevens meer sprake is van innovatie. Het lijkt gewenst om in A\&O-psychologische vraagstukken geïnteresseerde onderzoekers (hernieuwd) kennis te laten nemen van relevante methodologische ontwikkelingen.

Trefwoorden: geschiedenis van statistische methoden, inhoudsanalyse, arbeids- en organisatiepsychologie

\section{Inleiding}

Zowel arbeids- \& organisatie- als sociaal-psychologen zijn van oudsher geïnteresseerd in het gedrag van mensen in een bepaalde sociale context. In het tijdschrift Gedrag 4 ) Organisatie (G\&O) betreft die context vooral de arbeidsorganisatie, en om gedrag in arbeidssituaties te kunnen beschrijven, voorspellen en begrijpen, hebben we theorieën en onderzoeksmethoden nodig. Theorieën (onze ideeën over de manier waarop de wereld in elkaar steekt) helpen ons voor dat gedrag belangrijke concepten op te sporen (zoals attituden, normen, waarden, ander gedrag en persoonsfactoren, maar ook invloeden vanuit de omgeving). Onderzoeksmethoden zijn noodzakelijk om voor onze ideeen relevante gegevens op dusdanige wijze te verzamelen en te analyseren dat we iets zinnigs over de houdbaarheid ervan kunnen zeggen. Dat stelt eisen aan (i) de wijze waarop die gegevens worden gemeten (instrumentatie), (ii) het onderzoeksontwerp (design), en (iii) de manier waarop de gegevens worden

* Radboud Universiteit Nijmegen, **Universiteit Utrecht, ***TNO-Arbeid, Hoofddorp.

Correspondentieadres: Dr. T.W. Taris, Radboud Universiteit Nijmegen, Sectie Arbeids- en Organisatiepsychologie, Postbus 9104, 6500 HE Nijmegen. Telefoon: (024) 361 2639, fax (024) 361 5937, e-mail: t.taris@psych.ru.nl 
geanalyseerd (analyse) (Pedhazur \& Schmelkin, 1991). Instrumentatie heeft betrekking op de conceptualisatie en meting van relevante attributen (zoals attituden, gedrag, werk- en achtergrondkenmerken) van voor het onderzoek belangrijke entiteiten (bijvoorbeeld werknemers, hun taken, of de organisaties waarvoor zij werken). Het onderzoeksontwerp betreft de opzet, planning en uitvoering van het onderzoek; het oogmerk hiervan is gewoonlijk valide conclusies te trekken die naar andere steekproeven dan wel populaties gegeneraliseerd kunnen worden. Analyse ten slotte refereert aan de manier waarop de gegevens die voortkomen uit de instrumentatie- en ontwerpfase worden verwerkt (Austin, Scherbaum \& Mahlman, 2002).

Onderzoekers moeten in elk van deze drie domeinen keuzen maken; die keuzen hebben weer invloed op hetgeen we kunnen zeggen over de ideeën die we wilden onderzoeken. De afgelopen eeuw zijn de keuzemogelijkheden voor onderzoekers op elk van deze drie domeinen sterk toegenomen. Methodologen en statistici hebben in een hoog tempo allerlei vernieuwingen geïntroduceerd: zie de inhoudsopgaven van methodologisch gerichte tijdschriften en de schier onafzienbare reeks methodologische handboeken (de door Sage uitgegeven serie betreffende Quantitative applications in the social sciences omvat bijvoorbeeld inmiddels ruim 140 delen; elk daarvan bespreekt de fundamenten van een bepaalde onderzoekstechniek). Aangenomen mag worden dat toepassing van deze innovaties kan leiden tot een verhoging van de kwaliteit van onderzoek. In de nieuwe reeks De werkplaats wordt daarom aandacht besteed aan nieuwe, voor de lezers van G\&O relevante methodologische ontwikkelingen. Doel daarvan is enerzijds de actieve onderzoekers kennis te laten nemen van voor hen relevante methodologische ontwikkelingen. Anderzijds is het ook voor de lezers van belang om kennis te nemen van deze technieken, zodat zij in staat zullen blijven om de resultaten van onderzoek te interpreteren en te begrijpen. Bij wijze van inleiding van deze reeks zullen we de lezers een virtuele rondleiding geven op de werkplek van de auteurs van bijdragen aan G\&O. Doel daarvan is te zien welke instrumenten de gereedschapskist van publicerende onderzoekers bevat, zoals blijkt uit de in de afgelopen jaren in G\&O geplaatste bijdragen. De onderliggende premisse is dat deze rondleiding aanwijzingen kan geven betreffende de manier waarop toekomstig onderzoek in methodologisch opzicht vernieuwd en waar mogelijk verbeterd kan worden.

Hierna wordt in kort bestek een overzicht geschetst van belangrijke ontwikkelingen op elk van de drie hierboven onderscheiden methodologische domeinen (instrumentatie, onderzoeksontwerp, analyse), gebaseerd op een inventarisatie van de inhoud van de methodologische hoofdstukken in enkele arbeids- \& organisatiepsychologische handboeken. Per domein presenteren we daarna de resultaten van een analyse van 67 in de perioden 1990/1991 en 2002/2003 in G\&O verschenen empirische bijdragen. G\&O was in 1990, twee jaar na het opstarten van het blad, een redelijk gevestigd tijdschrift. De periode 2002/2003 werd gekozen omdat deze twee jaargangen in temporeel opzicht het verst verwijderd waren van de periode 1990/1991, zodat de kans op verschuivingen in het onderzoeksinstrumentarium werd gemaximaliseerd. De appendix bevat het gebruikte codeerschema; tabel 1 presenteert een beschrijving van de gecodeerde artikelen. 
Tabel 1 Kenmerken van de gecodeerde artikelen (standaardafwijkingen tussen haakjes)

\begin{tabular}{|c|c|c|c|c|c|c|}
\hline \multirow[b]{2}{*}{ jaar } & \multicolumn{2}{|c|}{ aantal artikelen } & \multirow[b]{2}{*}{ aantal auteurs ${ }^{a}$} & \multicolumn{3}{|c|}{ steekproefomvang ${ }^{a}$} \\
\hline & empirisch & overig & & gemiddelde & mediaan & scheefheid \\
\hline 1990/1991 & 33 & 27 & $2.3(1.0)$ & $446 \quad(563)$ & 185 & 2.1 \\
\hline $2002 / 2003$ & 34 & 27 & $3.0(1.4)$ & 858 (1527) & 359 & 4.0 \\
\hline
\end{tabular}

a Gebaseerd op de empirische artikelen.

In $\mathrm{G} \& \mathrm{O}$ werden in elk van de bestudeerde jaargangen ongeveer dertig artikelen gepubliceerd; ruim de helft daarvan beschreef de resultaten van een empirische studie. De andere bijdragen betroffen literatuuroverzichten (meta-analyses uitgezonderd) en (vooral) theoretische beschouwingen, bijvoorbeeld over de implementatie van automatiseringssystemen of de opzet en waarde van assessment centers. Kwalitatief onderzoek werd in G\&O niet of nauwelijks gepubliceerd, wat wellicht te wijten is aan de volgens Dehue (1995) aan Nederlandse universiteiten dominante empirisch-analytische traditie. Nietempirische bijdragen zijn buiten beschouwing gelaten.

Het gemiddeld aantal auteurs van een empirisch artikel is over de bestudeerde periode toegenomen. Waar in 1990/1991 nog 63\% van de empirische bijdragen één of twee auteurs telde, was dat in 2002/2003 voor slechts $32 \%$ het geval. Austin et al. (2002) vonden in hun analyse van de in het toonaangevende Journal of Applied Psychology (JAP) gepubliceerde artikelen een vergelijkbare trend. De omvang van de geanalyseerde steekproeven nam eveneens toe (mediane waarden waren 185 voor 1990/1991 en 359 voor 2002/2003; beide getallen laten zich uitstekend vergelijken met Austin et al.'s (2002) bevindingen, die voor 1990 een mediaan van 193 en voor 2000 een mediaan van 344 observaties vonden). Geconcludeerd mag worden dat de in G\&O gepubliceerde empirische artikelen over het bestudeerde interval de internationale trends ten aanzien van het aantal auteurschappen en steekproefomvang volgen. Maar kan datzelfde worden gezegd over de in de empirische artikelen gebruikte onderzoeksmethoden?

\section{Instrumentarium}

\subsection{De handboeken}

Zoals in veel academische disciplines is er voor de arbeids- \& organisatiepsychologie een breed scala aan inleidende overzichtswerken beschikbaar, vaak bedoeld als handboek bij een inleidende cursus in dit vakgebied. Een selecte en niet-representatieve inventarisatie laat zien dat zulke introducties gewoonlijk een hoofdstuk over "research methods in work and organizational psychology" bevatten (bijvoorbeeld Berry \& Houston, 1993; Dipboye, Smith \& Howell, 1994; Spector, 2004; en Statt, 2004). In potentie kunnen de in dergelijke hoofdstukken aan de orde komende onderwerpen inzicht verschaffen in de technieken die ten tijde van de uitgave van het desbetreffende werk belangrijk werden geacht. In de praktijk kennen deze hoofdstukken echter weinig verdieping en lijken ze inhoudelijk sterk op elkaar. Wat betreft het gebruikte instrumentarium wordt soms kort de omstreeks 1940 vrijwel uitontwikkelde klassieke testtheorie besproken (Spector, 2004), maar gewoonlijk wordt volstaan met de wat obligate aanbeveling om toch vooral betrouwbare en valide gegevens te verzamelen die betrekking hebben op een representatieve (wanneer men een survey- 
design gekozen heeft) dan wel gerandomiseerde (wanneer men een experimenteel design toepast) groep participanten. Over gedrags- dan wel fysiologische metingen wordt niet gesproken. Recentere ontwikkelingen in de testtheorie (zoals item-responsetheorie, IRT) komen niet aan de orde, wellicht omdat dit te moeilijk wordt geacht voor het beoogde publiek. In dit opzicht is het interessanter twee state-of-the-art handboeken op het gebied van de A\&O-psychologie te vergelijken. In 1990 werd de tweede editie van een door Dunnette en Hough geredigeerd vierdelig standaardwerk gepubliceerd, dat maar liefst vier methodologische hoofdstukken bevatte. Een qua opzet vergelijkbaar - zij het minder omvangrijk (twee delen, drie methodologische hoofdstukken) - boek verscheen in 2001 onder redactie van Anderson, Ones, Sinangil en Visweswaran. Voor ons doel zijn deze twee handboeken interessant, omdat ze wat betreft omvang en diepgang in potentie ook complexere en recentere technieken zouden kunnen bespreken. Omdat beide werken elf jaar na elkaar zijn verschenen is het niet onaannemelijk dat een vergelijking van de inhoud van de methodologische hoofdstukken interessante verschuivingen in de besproken onderzoeksmethoden zal laten zien. In tabel 2 wordt de inhoud van beide hoofdstukken op de eerdergenoemde hoofdlijnen vergeleken: (A) instrumentatie, (B) onderzoeksontwerp, en (C) analyse. Ook wordt in deze tabel kort aangegeven welke van de in beide handboeken besproken onderzoeksmethoden aan de orde komen in het recent door Rogelberg (2002) geredigeerde Handbook of research methods in industrial and organizational psychology.

Tabel 2 Vergelijking van de onderwerpen die in drie handboeken betreffende de arbeids\& organisatiepsychologie aan de orde komen

\begin{tabular}{|c|c|c|c|}
\hline & $\begin{array}{l}\text { Dunnette en } \\
\text { Hough } \\
\text { (red., 1990) }\end{array}$ & $\begin{array}{l}\text { Handboek } \\
\text { Anderson, } \\
\text { Ones, Sinangil } \\
\text { \& Visweswaran } \\
\text { (red., 2001) }\end{array}$ & $\begin{array}{l}\text { Rogelberg } \\
\text { (red., 2002) }\end{array}$ \\
\hline $\begin{array}{l}\text { A: Instrumentatie } \\
\text { Dataverzameling via internet } \\
\text { Klassieke testtheorie } \\
\text { Item-responstheorie } \\
\text { Adaptief testen }\end{array}$ & $\begin{array}{l}x \\
x\end{array}$ & $\begin{array}{l}x \\
x \\
x\end{array}$ & $\begin{array}{l}x \\
x \\
x\end{array}$ \\
\hline $\begin{array}{l}\text { B: Onderzoeksontwerp } \\
\text { Experiment } \\
\text { Veldexperiment } \\
\text { Survey } \\
\text { Simulatie } \\
\text { Observatie } \\
\text { Cohortonderzoek } \\
\text { Tijdreeksanalyse } \\
\text { Meta-analyse } \\
\text { Longitudinaal onderzoek }\end{array}$ & $\begin{array}{l}x \\
x \\
x \\
x \\
x \\
x \\
x \\
x \\
x\end{array}$ & $\begin{array}{l}x \\
x \\
x \\
x \\
x \\
x\end{array}$ & $\begin{array}{l}x \\
x \\
x \\
x\end{array}$ \\
\hline $\begin{array}{l}\text { C: Analyse } \\
\text { Power, effectgrootte } \\
\text { Uitbijters } \\
\text { Methodevariantie } \\
\text { Correlationele analyse } \\
\text { Regressieanalyse } \\
\text { Confirmatieve en } \\
\text { exploratieve factoranalyse } \\
\text { Structurele modellen } \\
\text { Multi-levelanalyse }\end{array}$ & $\begin{array}{l}x \\
x \\
x \\
x \\
x \\
x\end{array}$ & $\begin{array}{l}x \\
x \\
x\end{array}$ & $\begin{array}{l}x \\
x \\
x\end{array}$ \\
\hline
\end{tabular}

$X=$ Dit onderwerp komt in het desbetreffende handboek in meer of minder uitgebreide vorm aan de orde. 
Tabel 2, onderdeel A, laat zien dat in Dunnette en Hough (1991) uitgebreid wordt ingegaan op item-responsetheorie en op IRT gebaseerd adaptief testen (waarbij het aanbod van items tijdens de afname van een test door de computer wordt afgestemd op de antwoorden die de sollicitant gaf op eerdere items, om zo het niveau van de kandidaat preciezer vast te kunnen stellen). IRT wordt ook in het handboek van Anderson et al. besproken; adaptief testen wordt daarin echter niet genoemd. Opvallend genoeg komt de klassieke testtheorie er in het boek van Dunnette en Hough bekaaid af; er wordt in diverse hoofdstukken slechts zijdelings naar verwezen. In Anderson et al. (2001) wordt daarentegen wél uitgebreid ingegaan op de klassieke testtheorie. Daarin wordt ook enige aandacht besteed aan verschillende manieren om gegevens te verzamelen, waaronder dataverzameling via het internet - een onderwerp dat op het moment dat Dunnette en Hough hun bundels redigeerden nog niet aan de orde was. Aan drie van de vier in tabel 2 genoemde onderwerpen wordt ook in het methodologische handboek van Rogelberg (2002) een afzonderlijk hoofdstuk besteed (met uitzondering van adaptief testen). Op basis van dit beperkte overzicht kan voorzichtig worden geconcludeerd dat (i) de klassieke testtheorie en item-responsetheorie het afgelopen decennium belangrijke onderdelen van het instrumentarium van de A\&O-psycholoog vormden; (ii) dat adaptief testen inmiddels geen issue meer is; en (iii) dat dataverzameling via internet momenteel in het midden van de belangstelling staat. Maar in hoeverre komen deze trends terug in de door ons bestudeerde bijdragen aan $\mathrm{G} \& \mathrm{O}$ ?

\subsection{De artikelen}

Tabel 3 biedt een overzicht van het instrumentarium zoals gebruikt in de in G\&O gepubliceerde artikelen. Allereerst valt op dat in het overgrote deel van de studies sprake is van zelfrapportages (zoals vragenlijsten). Gedragsrapportages (bijvoorbeeld objectief gemeten ziekteverzuim, observationele data) komen minder vaak voor, en van (psycho-|fysiologische metingen is helemaal geen sprake. Het percentage studies waarin gedragsrapportages worden gebruikt, neemt gedurende de onderzochte periode af. Deze bevindingen komen ook naar voren uit Austin et al.'s (2002) studie, zij het dat gedragsrapportages in de door hen onderzochte artikelen duidelijk vaker vóórkomen.

Tabel 3 Instrumentarium: percentages artikelen waarin verschillende technieken worden gerapporteerd

\begin{tabular}{lcc}
\hline & $1990 / 1991$ & $2002 / 2003$ \\
\hline Wijze van dataverzameling & 84 & 97 \\
Zelfrapportages & 22 & 6 \\
Gedragsrapportages & 0 & 0 \\
Fysiologische metingen & & \\
\hline Herkomst instrumenten & 81 & 70 \\
Zelfontwikkeld & 52 & 91 \\
Elders ontwikkeld (niet-commercieel) & 7 & 30 \\
Elders ontwikkeld (commercieel) & & 100 \\
\hline Testtheoretische basis & 100 & 0 \\
Klassieke testtheorie & 5 & \\
Item-responstheorie & 5
\end{tabular}

N.B. De percentages sommeren niet tot 100 , omdat in één studie meerdere technieken naast elkaar kunnen worden gebruikt. 
In G\&O publicerende onderzoekers maken in veel gevallen gebruik van ad hoc ontwikkelde schalen, zij het dat zulks anno 2002/2003 iets minder vaak gebeurt dan in 1990/1991 (respectievelijk 70\% en $81 \%$ ). Men gebruikt tegenwoordig duidelijk vaker elders ontwikkelde en gevalideerde instrumenten dan aan het begin van de onderzochte periode (91\% om $52 \%)$. Commercieel verkrijgbare instrumenten worden in 1990/1991 in 7\% van de artikelen gebruikt, terwijl zulks in 2002/2003 in 30\% van de artikelen het geval was. Een en ander suggereert dat de in G\&O publicerende onderzoekers tegenwoordig meer dan vroeger voortbouwen op de resultaten van andere onderzoekers (wat wellicht te danken is aan een afnemende diversiteit van het onderzoek in de A\&O-psychologie), dan wel dat er meer goede (standaard)instrumenten beschikbaar zijn. Tegelijkertijd blijft het percentage studies waarin ad hoc ontwikkelde instrumenten worden toegepast aanzienlijk.

Ten slotte laat tabel 3 zien dat A\&O-psychologen geen boodschap hebben aan recente ontwikkelingen in de testtheorie. In vrijwel alle studies waarin concepten met meerdere items worden gemeten, wordt uitgegaan van de klassieke testtheorie. IRT wordt in 1990/1991 in 5\% van de studies toegepast, maar het gaat daarbij welgeteld om één onderzoek. Sterk vergelijkbare percentages worden gerapporteerd door Austin et al. (2002): zij suggereren dat de complexiteit van veel IRT-modellen een grote populariteit in de weg staat.

\section{Onderzoeksontwerp}

\subsection{De handboeken}

De inleidende handboeken in de A\&O-psychologie bespreken de ins en outs van eenvoudige (quasi-)experimentele proefopzetten, alsook niet-experimentele opzetten (surveys). Ook de door ons gescreende state-of-the-art handboeken bespreken deze materie, zij het een stuk uitgebreider en diepgaander (tabel 2). Daarnaast worden in deze handboeken enkele aanvullende onderzoeksontwerpen besproken. In de door Dunnette en Hough (1990) geredigeerde bundel wordt relatief veel aandacht geschonken aan simulatieonderzoek; dit onderwerp komt ook in Rogelberg (2002) expliciet aan de orde, maar wordt in het handboek van Anderson et al. (2001) niet genoemd. In Dunnette en Hough (1990) wordt zowel cohortonderzoek als tijdreeksanalyse besproken; beide onderwerpen worden in de twee recentere handboeken vrijwel volledig genegeerd. Daarentegen ontvangen meta-analyse en longitudinaal onderzoek in de recente handboeken veel aandacht, terwijl deze onderwerpen in 1990 niet werden genoemd.

\subsection{De artikelen}

In tabel 4 worden de in 1990/1991 en 2002/2003 gebruikte onderzoeksdesigns gekarakteriseerd. De meeste gepubliceerde studies worden uitgevoerd in het veld. Laboratoriumonderzoek is daarentegen niet populair en het aantal studies waarin daarvan gebruik wordt gemaakt neemt zelfs af $115 \%$ voor 1990/1991, tegen 6\% voor 2002/2003). Meta-analyses en simulatiestudies werden in de onderzochte jaren nauwelijks in G\&O gepubliceerd. In Austin et al.'s (2002) studie blijkt eveneens dat laboratoriumstudies in de A\&O-psychologie relatief impopulair zijn. (Quasi-/experimentele onderzoeksdesigns werden in 1990/1991 in eenderde van de onderzochte studies toegepast; tien jaar later was dat nog $11 \%$. De populariteit van observationele designs - waarin geen variabelen worden gemanipuleerd - is in die periode dienovereenkomstig toegenomen (van 64\% naar 89\%); archiefstudies werden in de onderzochte 
perioden niet gepubliceerd. Ter vergelijking, in 2000 bestond volgens Austin et al. (2002) 43\% van de in dat jaar in het Journal of Applied Psychology gepubliceerde studies uit archiefstudies en (quasi-lexperimentele studies. Ten slotte blijkt dat ruim $80 \%$ van de in G\&O gepubliceerde studies een cross-sectionele opzet (dat wil zeggen, met één meetmoment) kent. De gerapporteerde longitudinale studies kennen vrijwel altijd twee metingen. Het percentage longitudinale onderzoeken in G\&O steekt in 1990/1991 gunstig af bij de in JAP gepubliceerde studies, waar in 1990 slechts $5 \%$ van de studies een longitudinaal karakter had (Austin et al., 2002). In 2000 was dit aandeel gestegen tot $15 \%$, hetgeen ongeveer gelijk is aan het percentage in G\&O.

Tabel 4 Onderzoeksontwerp: percentages artikelen waarin bepaalde benaderingen worden toegepast

1990/1991

$2002 / 2003$

Context van het onderzoek

Laboratorium

Veldstudie

Meta-analyse

Simulatie

$2002 / 2003$

\section{Onderzoeksontwerp}

(Quasi-)experimenteel

Observationeel/passief

Archiefstudie

$\begin{array}{rr}15 & 6 \\ 82 & 94 \\ 3 & 0 \\ 0 & 0\end{array}$

Tijd

Cross-sectioneel

Longitudinaal

36

64

11

11
0

6
4
0
0
1
9
0

0

\section{Analyse}

\subsection{De handboeken}

De als inleiding in de A\&O-psychologie bedoelde werken beperken zich hier tot een bespreking van de berekening van gemiddelden en standaardafwijkingen en eenvoudige associatiematen (zoals chi-kwadraattoetsen, correlatiecoëfficiënten en $T$-toetsen - technieken die medio vorige eeuw waren uitontwikkeld, Cowles, 2001). De hoofdstukken in de state-of-the-art handboeken gaan ook hier duidelijk verder (tabel 2). Het opvallendste verschil tussen het in 1990 gepubliceerde handboek van Dunnette en Hough en dat van Anderson et al. (2001) en Rogelberg (2002) betreft de aandacht die in de twee recentere boeken wordt besteed aan multi-levelanalyse; een onderwerp dat in 1990 nog niet op de agenda stond. Alle andere in tabel 2 genoemde onderwerpen komen zowel in 1990 als in ten minste één van de twee recent verschenen handboeken terug.

\subsection{De artikelen}

Tabel 5 geeft een overzicht van de statistische analysetechnieken die in de gedurende de onderzochte perioden verschenen artikelen werden toegepast. Meest opvallend is dat tussen 1990/1991 en 2002/2003 regressie-achtige benaderingen in populariteit toenamen. In 1990/1991 werd in 34\% van de gevallen een regressiebenadering (inclusief structureel modelleren) toegepast; ruim tien jaar later wordt in $77 \%$ van de artikelen een vorm van regressieanalyse 
(inclusief structureel modelleren en multi-levelanalyse) gebruikt (dit percentage is niet afleesbaar uit tabel 5, omdat in een artikel meerdere technieken naast elkaar kunnen worden gebruikt; vooral de combinatie van multi-levelanalyse met regressieanalyse komt vaak voor).

Tabel 5 Analyse: percentages artikelen waarin bepaalde analysetechnieken worden toegepast

\begin{tabular}{|c|c|c|}
\hline & 1990/1991 & $2002 / 2003$ \\
\hline Correlaties & 44 & 67 \\
\hline Chi-kwadraattoets & 9 & 6 \\
\hline T-toets & 9 & 30 \\
\hline$(M) A N(C) O V A{ }^{a}$ & 42 & 38 \\
\hline Exploratieve factoranalyse & 3 & 15 \\
\hline (Hiërarchische) regressieanalyse & 31 & 58 \\
\hline Confirmatieve factoranalyse/structureel modelleren ${ }^{b}$ & 3 & 15 \\
\hline Multi-levelanalyse & 0 & 15 \\
\hline Poweranalyse & 0 & 0 \\
\hline Effectmaten & 0 & 15 \\
\hline
\end{tabular}

a ANOVA, MANOVA, ANCOVA en MANCOVA zijn vier verwante technieken die historisch gezien op verschillende momenten werden ontwikkeld. Ze zijn hier samengevoegd omdat het bij het beoordelen van de in G\&O verschenen artikelen vaak onduidelijk was welke variant er precies werd gebruikt.

b Hier gaat het om twee zeer sterk verwante en gelijk ontwikkelde technieken die regelmatig tegelijk worden toegepast. Vanwege geringe celvullingen achtten we het niet zinvol beide benaderingen te onderscheiden.

Sowieso wordt er anno 2002/2003 veel meer getoetst en worden er vaker toetsen naast en in aanvulling op elkaar gebruikt. Waar in 1990/1991 soms werd volstaan met uitsluitend de presentatie van enkele al dan niet significante correlaties of chi-kwadraatwaarden, is het tegenwoordig bepaald niet ongebruikelijk om in één artikel zowel een discussie van de significante correlaties in de correlatietabel als enkele variantieanalyses als een regressieanalyse te vinden. Opvallend is verder dat "eenvoudige" regressieanalyse tegenwoordig nog steeds populairder is dan het gebruik van structurele modellen $158 \%$ vs. $15 \%$ ), ondanks het feit dat er inmiddels enkele generaties onderzoekers zijn getraind in het gebruik van programma's als LISREL, EQS en AMOS, alsmede de reeds jarenlange beschikbaarheid van grafische hulpprogramma's die de gebruiker helpen dit soort programma's toe te passen. Austin en collega's (2002) vinden in hun analyse van de in 2000 in JAP verschenen artikelen overigens vergelijkbare percentages; $\mathrm{G} \& \mathrm{O}$ wijkt ook hier niet sterk af van de internationale trend. Ten slotte laat tabel 5 zien dat er in 2002/2003 in 15\% van de artikelen een indicatie van de grootte van de gevonden effecten wordt gepresenteerd (vaak Cohens $D$ of èta-kwadraat). Poweranalyses, dat wil zeggen analyses waarin het onderscheidingsvermogen van de gevolgde toetsprocedure wordt bekeken, kwamen we op geen van beide tijdstippen tegen.

\section{Discussie}

Onderzoekers die zich bezighouden met A\&O-psychologische vraagstukken, beschikken over een brede verscheidenheid aan onderzoeksmethoden. In de methodologische hoofdstukken in inleidende boeken in de A\&O-psychologie blijkt daarvan weinig. Meestal is er sprake van beknopte discussies van de eenvoudigste beginselen van onderzoek, zoals betrouwbaarheid, validiteit, 
klassieke testtheorie, experimenteel versus survey-onderzoek, berekenen van gemiddelden en eenvoudige associatiematen - methoden die grotendeels werden ontwikkeld aan het begin van de vorige eeuw. Veel bredere en dieper gravende overzichten vindt men in de op gevorderden gerichte meerdelige handboeken. Daarin komen ook recentere en meer geavanceerde methoden (zoals IRT, confirmatieve factoranalyse, structureel modelleren en multi-levelanalyse) aan de orde, en deze lijken de methodologische stand van zaken dan ook goed weer te geven.

Deze ontwikkelingen komen slechts ten dele terug in de door ons geanalyseerde G\&O-artikelen. Wat betreft het gebruikte instrumentarium lijken recente methodologische ontwikkelingen nauwelijks voet aan de grond te krijgen. Onderzoekers staan in dit opzicht met beide benen stevig in het midden van de vorige eeuw; de klassieke testtheorie is heer en meester, en ontwikkelingen zoals IRT zijn niet of nauwelijks van betekenis. Dat is des te opvallender, omdat in de Nederlandse A\&O-opleidingen relatief veel aandacht aan testtheorie wordt besteed en Nederland op dit gebied enkele prominente onderzoekers kent. Internationaal is eenzelfde trend zichtbaar. Zo concluderen Austin et al. (2002) dat "In measurement, a major [unfinished innovation] is incomplete adaptation of IRT ... despite cogent arguments for [its] use" $^{\prime \prime}$ (p. 20). Verder valt hier op dat onderzoekers vaker gebruik lijken te maken van gestandaardiseerde instrumenten. Zelfontwikkelde, ad-hoc-operationalisaties blijven echter belangrijk, terwijl gegevens overwegend via zelfrapportages worden verzameld - althans in G\&O. Internationaal wordt duidelijk meer belang gehecht aan objectieve gedragsrapportages (Austin et al., 2002). Een voor de hand liggende reden daarvoor is dat Austin en collega's zich richtten op misschien wel het meest gerenommeerde tijdschrift in de A\&Opsychologie, dat daarom ook de hoogste eisen aan bijdragen kan stellen. Hadden we de vergelijking gezocht met een internationaal middenklasse-tijdschrift dan zouden we wellicht hebben geconstateerd dat ook daar in overwegende mate sprake is van zelfrapportages.

Ook wat betreft het onderzoeksontwerp komen recente ontwikkelingen nauwelijks in de gepubliceerde artikelen terug. In de door ons geanalyseerde $\mathrm{G} \& \mathrm{O}-$ artikelen is nog steeds vooral sprake van cross-sectionele veldstudies waarin de variabelen niet door de onderzoeker gemanipuleerd worden; een trend die zelfs lijkt toe te nemen. Studies met een (quasi-)experimentele opzet, al dan niet uitgevoerd in het laboratorium, komen in de recente jaargangen van G\&O weinig voor. Eén mogelijke reden daarvoor is dat de door de Associatie van Sociaal-Psychologische Onderzoekers (ASPO) uitgegeven reeks jaarboeken Sociale Psychologie zich in toenemende mate lijkt te ontwikkelen tot een voor sociaal-psychologen interessant podium. Bijdragen uit die hoek (die vaak een experimenteel karakter hebben) zouden daarom niet meer in G\&O terecht kunnen komen, ook niet als zij daarin inhoudelijk uitstekend zouden passen. In dit opzicht is het door G\&O beslagen terrein het afgelopen decennium kleiner geworden, wat weer kan betekenen dat G\&O minder representatief is geworden voor de Nederlandse arbeids- en organisatiepsychologie.

Een andere verklaring is dat er de afgelopen jaren een verandering heeft plaatsgevonden in het onderzoeks- en publicatiegedrag van Nederlandse onderzoekers. Als gevolg van het publish or perish-klimaat in de Nederlandse universiteiten (vergelijk Schruijer, 2004) zouden onderzoekers geneigd kunnen zijn vooral studies uit te voeren waarin gebruik wordt gemaakt van zelfrapportages, veldstudies en cross-sectionele, observationeel-passieve designs. Dit type studies is relatief weinig arbeidsintensief en daarmee een efficiënte 
manier om een lange publicatielijst te genereren. De bevinding dat er steeds meer auteurs meewerken aan een artikel past bij deze interpretatie: wanneer er veel publicaties worden verlangd doen onderzoekers minder arbeidsintensieve studies met meer auteurs, dat levert voor iedereen meer op.

Wat betreft het analysedomein lijken onderzoekers meer tot innovatie bereid dan op de twee andere domeinen. Hoewel relatief eenvoudige technieken als correlatieanalyse en univariate variantieanalyse populair blijven, dienen die anno 2002/2003 vooral als aanvulling op dan wel inleiding van meer complexe, multivariate analyses (vooral regressieanalyse, maar ook structureel modelleren en multi-levelanalyse). Blijkbaar bieden deze nieuwere technieken een duidelijke meerwaarde ten opzichte van oudere benaderingen, waardoor onderzoekers bereid zijn deze relatief complexe methoden te leren gebruiken én toe te passen. Dat impliceert overigens dat de empirische artikelen in $\mathrm{G} \& \mathrm{O}$ in toenemende mate minder toegankelijk worden voor het algemene in A\&O-psychologische onderwerpen geïnteresseerde publiek. G\&O-lezers moeten in toenemende mate beschikken over een behoorlijke statistische kennis om dit soort artikelen te kunnen volgen.

Samenvattend, onze studie laat zien dat onderzoekers in de A\&O-psychologie tegenwoordig beschikken over een breed arsenaal aan onderzoeksmethoden om hun theorieën te toetsen. Dat kan positieve gevolgen hebben voor de kwaliteit van hun onderzoek, maar dat vereist wel dat onderzoekers de moeite moeten nemen om zich te verdiepen in mogelijk relevante technieken. Onze inventarisatie van de in 1990/1991 en 2002/2003 in Gedrag \&) Organisatie verschenen artikelen suggereert echter dat methodologische innovaties slechts moeizaam doordringen tot de praktisch georiënteerde onderzoeker (met uitzondering van het analysedomein, waar nog wel van enige innovatie sprake lijkt). De hier gesignaleerde trends zijn niet uniek voor G\&O. Onze vergelijking met een identieke inventarisatie van artikelen in het Journal of Applied Psychology (Austin et al., 2002) laat zien dat ook daar methodologische innovaties grotendeels afwezig zijn.

We hebben niet de pretentie om Nederland in het algemeen en Gedrag 4 Organisatie in het bijzonder als gidsland of gidstijdschrift op de kaart te zetten. Het lijkt echter wel gewenst om in A\&O-psychologische vraagstukken geïnteresseerde lezers en onderzoekers (hernieuwd) kennis te laten nemen van relevante methodologische ontwikkelingen. Wij hopen dat onze nieuwe reeks $D e$ werkplaats in dat opzicht de disseminatie van methodologische vernieuwingen zal bevorderen. Ten slotte willen we geïnteresseerden van harte uitnodigen om een bijdrage aan deze reeks te leveren. In het aprilnummer van de jaargang 2004 van Gedrag $\uplus$ Organisatie vindt u de bij deze reeks behorende call for papers. Voor nadere informatie kunt u contact opnemen met één van de drie auteurs van deze bijdrage; zij fungeren tevens als redacteur van de reeks.

\section{Dankwoord}

De auteurs danken dr. Herman Steensma, dr. Wim van Breukelen, prof. dr. Daan van Knippenberg en prof. dr. Wilmar Schaufeli voor hun waardevolle commentaren op een eerdere versie van dit stuk. 


\section{Literatuur}

Anderson, N., Ones, D.W., Sinangil, H.K. \& Visweswaran, C. (2001). Handbook of industrial, work and organizational psychology. London: Sage.

Austin, J.T., Scherbaum, C.A. \& Mahlman, R.A. (2002). History of research methods in industrial and organizational psychology: Measurement, design, analysis. In S.G. Rogelberg (red.), Handbook of research methods in industrial and organizational psychology (pp. 3-33). Malden (MA): Blackwell.

Berry, L.M. \& Houston, J.P. (1993). Psychology at work: An introduction to industrial and organizational psychology. Madison: Brown \& Benchmark Publishers.

Cowles, M. (2001). Statistics in psychology: An historical perspective (2e editie). Hillsdale (NJ): Erlbaum.

Dipboye, R.L., Smith, C.S. \& Howell, W.C. (1994). Understanding industrial and organizational psychology: An integrated approach (3e editie). Fort Worth: Harcourt.

Dehue, T. (1995). Changing the rules: Psychology in the Netherlands, 1900-1985. Cambridge: Cambridge University Press.

Pedhazur, E. \& Schmelkin, L. (1991). Measurement, design, and analysis. Hillsdale: Erlbaum.

Rogelberg, S.G. (red., 2002), Handbook of research methods in industrial and organizational psychology. Malden (MA): Blackwell.

Schruijer, S.G.L. (2004). Naar ontzuiling en samenwerking in de studie van gedrag en organisatie. Gedrag e) Organisatie, 17, 303-309.

Spector, P.E. (2004). Industrial and organizational psychology: Research and practice (3e editie). New York: Wiley.

Statt, D.A. (2004). Psychology and the world of work (3e editie). Basingstoke: Palgrave MacMillan.

\section{Summary}

\section{Gedrag \&) Organisatie through the years: What methodological tools do researchers in I/O psychology employ?}

Toon Taris, Jan de Jonge \& Jan Fekke Ybema, Gedrag Æ Organisatie, Volume 18, February 2005, nr. 1, pp. 47-57

The present study examines to what extent methodological innovations disseminate to researchers in I/O psychology. First we examined which issues are discussed in the methodological chapters of a variety of introductory and advanced textbooks in the field of I/O psychology. Based on this inventory, we content-analyzed 67 empirical articles that appeared in the Dutch journal Gedrag et Organisatie, in 1990/1991 and 2002/2003. The results show that methodological innovations with regard to the measurement of concepts and design of studies are largely absent. However, researchers seem more open to innovations with regard to analysis of their data. It is concluded that it is desirable that $I / O$ researchers become (re)acquainted with relevant methodological developments.

Key words: history of statistical methods, content-analysis, work and organizational psychology 